\title{
The role of weakness of triceps surae muscles in astasia without abasia
} Kenji Hachisuka, Akio Ohnishi, Makio Yamaga, Koichiro Dozono, Mari Ueta,
Hajime Ogata
Department of Rehabilitation Medicine K Hachisuka K Dozono M Ueta H Ogata

Department of Neurology, University of Occupational and Environmental Health, Japan

A Ohnishi

Department of Rehabilitation Medicine, Faculty of Medicine, Kumamoto University M Yamaga

Correspondence to:

Dorrespondence to:

Department of Rehabilitation

Medicine, University of

Medicine, University

Occupational and Environmental Health, 1-1 Kitakyushu, 807, Japan.

Received 24 September 1996 and in revised form 18 December 1996 Accepted 8 January 1997

\begin{abstract}
Objective-To investigate the role of weakness of the bilateral triceps surae muscles-the gastrocnemius and soleus muscles-in astasia without abasia and whether compensating for muscle weakness with ankle-foot orthoses improves this disability.
\end{abstract}

Design-Case-control study of clinical findings and before and after trial of ankle-foot orthoses.

Setting-Clinics of the departments of rehabilitation medicine of two university hospitals.

Patients-A stilts group consisting of 23 patients with astasia without abasia, and a non-stilts group without this phenomenon consisting of 12 patients with hereditary motor sensory neuropathy, 15 patients with lumbosacral spondylotic radiculopathy or spondylolisthesis, and 20 healthy volunteers.

Main outcome measure-Clinical findings of the stilts and non-stilts groups were compared and the sensitivity and specificity of each clinical finding was calculated. The length of the centre of foot pressure (COP) while standing was measured in a bilateral below knee amputee and 16 consecutive patients in the stilts group with and without ankle-foot orthoses.

Results-Weakness of the triceps surae muscles was the only finding that differed significantly between the two groups and was both sensitive and specific. The amputee was unable to stand in place without dorsiflexion bumpers, which functioned similarly to the triceps surae muscle. Bilateral ankle-foot orthoses improved the COPs of 14 out of 16 patients.

Conclusion-The main cause of astasia without abasia is weakness of the triceps surae muscles, and this disability is improved by bilateral ankle-foot orthoses.

(F Neurol Neurosurg Psychiatry 1997;62:496-500)

Keywords: astasia without abasia; disturbance of stance; stilts phenomenon; peripheral neuropathy

Although it is generally thought that a person who is able to walk is able to stand, we have encountered patients who are able to walk but unable to stand in one place. This curious disability can occur in patients with muscular weakness and sensory disturbance of the lower limbs caused by peripheral neuropathies, spinal root or spinal cord lesions, and myopathies. The symptom was named "astasia without abasia" by Hirayama et $a l^{12}$ and is defined as an inability to maintain a stationary position to assume and keep an upright posture, although the legs are under control in walking. No other reports of the disability have been found. As a patient with astasia without abasia resembles a child on stilts who walks steadily but continuously steps forward and backward while trying to stand in place, it is also called the "stilts phenomenon." 2 Hirayama $e t a l^{2}$ suggested that astasia without abasia is caused by a combination of three conditions: (1) loss of the ankle pattern of postural movements because of decreased muscular strength and tone about the ankle joints; (2) lack of compensatory postural movements by the hip pattern, which is dependent on sufficient strength about the hip joints; and (3) impairment of somatosensory feedback from the legs for postural stabilisation.

We have noticed that a patient who had weakness of the bilateral triceps surae muscles without sensory disturbances had astasia without abasia that improved with ankle-foot orthoses. Therefore, we examined patients who had and others who did not have astasia without abasia to determine what part weakness of the triceps surae muscle-which is composed of gastrocnemius and soleus muscles-plays in astasia without abasia and whether compensating for the muscle weakness with ankle-foot orthoses reduces this disability.

\section{Patients and methods}

This investigation consisted of three studies: statistical analysis of physical findings of patients with astasia without abasia; measurement of the stability of a bilateral below-knee amputee while standing; and evaluation of the efficacy of ankle-foot orthoses.

\section{STUDY 1}

Clinical criteria for astasia without abasia were devised by two of us (KH and MY) as follows: (1) a patient can keep the body more stable while walking than while standing and (2) a patient takes a step or must be supported within one minute after beginning to stand in place. Astasia without abasia was considered mild when a patient fulfilled only the first criterion and was considered severe when a patient fulfilled both criteria. Twenty three consecu- 
tive patients with astasia without abasia (stilts group) were identified from among patients who were referred to clinics at the Department of Rehabilitation Medicine, University of Occupational and Environmental Health Hospital, and at Kumamoto University Hospital for further rehabilitation from 1988 to the end of 1995. Clinical diagnoses of patients were previously established at the departments of neurology or orthopaedic surgery as follows: hereditary motor sensory neuropathy (five patients); spinal progressive muscular atrophy (two); acute inflammatory demyelinating polyradiculoneuropathy (two); familial amyloid polyneuropathy (two); hereditary sensory autonomic neuropathy (one); vasculitic neuropathy (one); beriberi (one); peripheral neuropathy of unknown aetiology (two); distal myopathy with rimmed vacuoles (one); myotonic dystrophy (one); cauda equina injury (two); lumbosacral spondylotic radiculopathy (one); spondylolisthesis (one); and myelomeningocele (one).

Forty eight subjects who did not fulfil the criteria for astasia without abasia (non-stilts group) consisted of 12 patients with hereditary motor sensory neuropathy (NS-HMSN), 15 patients with lumbosacral spondylotic radiculopathy or spondylolisthesis (NS-LSR), and 20 healthy control subjects (NS-C). The NSHMSN group consisted of consecutive patients referred to the clinic at the Department of Rehabilitation Medicine for gait training. The NS-LSR group consisted of consecutive patients referred to the clinic for muscle strengthening and gait training after surgery of the lumbar spine, and had weakness in the unilateral tibialis anterior or triceps surae muscles or both. The NS-C group consisted of volunteers who had never had neuromuscular disorders.

Neuromuscular testing was performed with standard techniques in all subjects. Muscle strength of the iliopsoas, gluteus maximus, quadriceps femoris, hamstrings, tibialis anterior, and triceps surae muscles was manually

Figure 1 The below-knee prosthesis. The lateral half of the artificial foot is removed to show the mechanism of the superankle. The dorsiflexion bumper supports the shaft and prevents excessive dorsiflexion while standing. evaluated as $5,4,3,2,1$, or $0^{3}$; muscle weakness was defined as muscle strength of 2 or less. Range of motion of the ankle joint was measured with a goniometer, ${ }^{4}$ and limitation of the range of motion was defined as a range of motion of $5^{\circ}$ or less. Muscle stretch reflexes of the knee and ankle were elicited with a hammer, and absent or diminished reflexes of the knee and absent reflexes of the ankle were defined as diminution of the muscle stretch reflex. ${ }^{5}$ Touch and pain on the dorsum of the foot and position and vibration sense of the great toe were rated as "severely disturbed," "moderately disturbed," "slightly disturbed," or "normal", 5 and a sensation of less than normal was defined as sensory disturbance. Coordination of the lower limbs was rated as "disturbed," "slightly disturbed" or "normal", ${ }^{5}$ and coordination of the less than normal was defined as ataxia. Each result of the tests was converted into "no disturbance," "unilateral disturbance," or "bilateral disturbance" to allow use of the $\chi^{2}$ test.

For the five patients in the stilts group in whom sensory disturbances were not found during physical examination, sural nerve conduction velocities, ${ }^{6}$ somatosensory evoked potentials (SEPs) to tibial nerve stimulation, ${ }^{7}$ and cutaneous vibration and thermal cooling thresholds $^{8}$ were evaluated to confirm the presence or absence of sensory abnormalities.

\section{STUDY 2}

To study whether compensating for weak triceps surae muscles improves stability while standing, the length of the centre of foot pressure (COP) was measured in a patient who had had both legs amputated below the knee five years earlier because of frostbite. The patient had normal muscular strength in the lower limbs; had no disturbances of touch, pain, position, or vibration sense of the stumps; and was able to walk and run with prostheses. ${ }^{9}$ Results of SEP studies were normal. The COP was taken as the projection of the centre of gravity on to the force plates (Kistler, Switzerland), on which the amputee stood for 30 seconds with the artificial feet (Superankle C), LAPOC, Japan) maintained at $40^{\circ}$ between the feet and the eyes open. Each measurement was repeated five times before and after dorsiflexion bumpers, which prevented excessive dorsiflexion of the feet, were attached to the feet (fig 1). The COPs were expressed in $\mathrm{cm} / 30 \mathrm{~s}$, and the average was calculated with a personal computer (PC9801BA, NEC, Japan). When the amputee took a step or was supported by members of the medical staff during the measurement at least once per five trials, the COP was defined as unmeasurable.

STUDY 3

Ankle-foot orthoses ${ }^{10}$ were fitted for 22 patients in the stilts group to improve stability while standing; a foot orthosis ${ }^{10}$ was made for one patient because of ulcers on the bottom of the feet. Patients subjectively evaluated stability while standing with orthoses as worse, unchanged, improved, and much improved. 
Comparison of clinical findings between the stilts and non-stilts groups

\begin{tabular}{|c|c|c|c|c|c|}
\hline & $\begin{array}{l}\text { Stilts } \\
\text { group } \\
(n=23)\end{array}$ & $\begin{array}{l}\text { Non-stilts } \\
\text { group } \\
(n=47)\end{array}$ & Pvalue & Sensitivity & Specificity \\
\hline \multicolumn{6}{|l|}{ Muscular weakness: } \\
\hline Bil gluteus maximus & 5 & 1 & 0.006 & $0 \cdot 83$ & $0 \cdot 72$ \\
\hline Unil gluteus maximus & 0 & 6 & $0 \cdot 168$ & 0.00 & 0.64 \\
\hline Bil tibialis anterior & 18 & 4 & $<0.001$ & 0.82 & $0 \cdot 90$ \\
\hline Unil tibialis anterior & 0 & 4 & $0 \cdot 150$ & 0.00 & 0.65 \\
\hline Bil triceps surae & 22 & 1 & $<0.001$ & 0.96 & 0.98 \\
\hline Unil triceps surae & 0 & 5 & $0 \cdot 164$ & 0.00 & 0.65 \\
\hline \multicolumn{6}{|c|}{ Limitation of range of motion: } \\
\hline Bil ankle joints & 2 & 6 & 0.615 & 0.25 & 0.66 \\
\hline Unil ankle joint & 0 & 1 & $1 \cdot 000$ & 0.00 & 0.67 \\
\hline \multicolumn{6}{|l|}{$\begin{array}{l}\text { Diminution of muscle } \\
\text { stretch reflex: }\end{array}$} \\
\hline Bil knee joints & 15 & 13 & 0.003 & 0.54 & $0 \cdot 81$ \\
\hline Unil knee joint & 0 & 1 & $1 \cdot 000$ & 0.00 & 0.67 \\
\hline Bil ankle joints & 23 & 13 & $<0.001$ & 0.64 & 1.00 \\
\hline Unil ankle joint & 0 & 14 & 0.003 & 0.00 & 0.59 \\
\hline \multicolumn{6}{|l|}{ Sensory disturbances: } \\
\hline Touch on bil dorsi & 16 & 16 & 0.005 & 0.50 & $0 \cdot 82$ \\
\hline Touch on unil dorsum & 0 & 8 & 0.046 & 0.00 & 0.63 \\
\hline Pain on bil dorsi & 16 & 16 & 0.005 & 0.50 & 0.82 \\
\hline Pain on unil dorsum & 1 & 8 & 0.254 & $0 \cdot 11$ & 0.64 \\
\hline Position of bil toes & 15 & 12 & 0.001 & 0.56 & $0 \cdot 81$ \\
\hline Position of unil toe & 0 & 6 & 0.076 & 0.00 & 0.64 \\
\hline Vibration on bil toes & 17 & 15 & 0.001 & 0.53 & 0.84 \\
\hline Vibration on unil toe & 0 & 6 & $0 \cdot 168$ & 0.00 & 0.64 \\
\hline
\end{tabular}

Muscular weakness of the iliopsoas, quadriceps, and hamstrings, and coordination are not shown because of low frequencies. bil = bilateral; unil = unilateral; dorsi $=$ dorsi of the feet; dorsum $=$ dorsum of the foot; toe $(s)=b i g$ toe $(s)$.

The COP was also measured in 16 consecutive patients in the stilts group.

\section{STATISTICAL METHODS}

Student's $t$ test and one way analysis of variance (ANOVA) were used to examine the differences in age between the stilts and non-stilts groups and among the NS-HSMN, NS-LSR, and NS-C groups. The $\chi^{2}$ test was used to detect any difference in sex ratio between the two groups. Each clinical finding between the two groups was compared using the $\chi^{2}$ test and Fisher's exact test, if necessary. Sensitivity was the rate of patients with astasia without abasia among those having a finding, and specificity was the rate of patients without astasia without abasia among those not having a finding. Student's $t$ test was used to compare COPs between trials with and without orthoses.

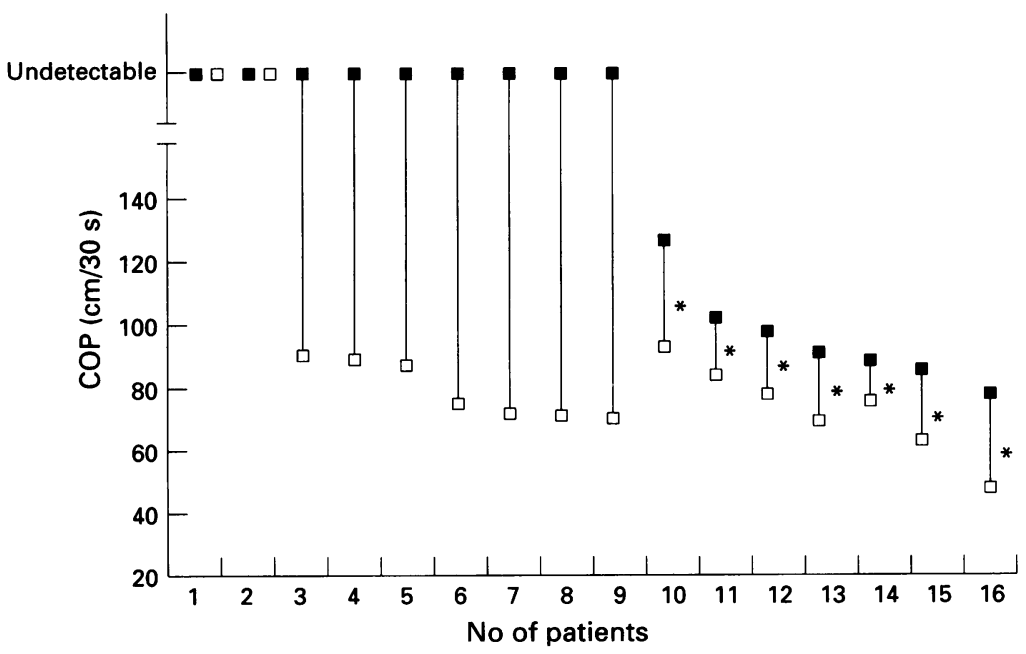

Figure 2 The COP values of 16 consecutive patients in the stilts group with and without ankle-foot orthoses. Each patient's COPs with and without ankle-foot orthoses were linked. The COPs decreased considerably in seven patients while wearing ankle-foot orthoses (Nos 3 to 9), decreased significantly in another seven (Nos 10 to 16), and were unmeasurable (patient took a step or was supported at least once per five trials) either with or without orthoses in two (Nos 1 and 2), although the patients claimed improvements. COP = average length of the centre of foot pressure (cm/30 seconds); $\square=$ without orthoses; $\square=$ with orthoses; $P<0.05$; Student's $t$ test.

\section{Results}

STUDY 1

In the stilts group patients had peripheral neuropathies, spinal root lesions, or distal dominant myopathies, and astasia without abasia was mild in 15 patients and severe in eight. Differences in age were not significant either between the stilts (mean (SD) $45.9(18 \cdot 1)$ years,) and non-stilts groups $(40.4(12 \cdot 3)$ years; $\mathrm{df}=68, \quad t=1.51, \quad \mathrm{P}=0.136)$ or among the three subgroups of the non-stilts group (NS-HMSN, 37.2 (13.6) years; NSLSR, 39.7 (13.9) years; NS-C, $42 \cdot 8(10 \cdot 4)$ years; $\mathrm{df}=46, F=0.788, P=0.461)$. Sex ratios (male:female) did not differ significantly between the stilts $(10: 13)$ and non-stilts groups $\left(28: 19 ; \mathrm{df}=1, \chi^{2}=1.612, \quad \mathrm{P}=\right.$ $0 \cdot 204)$.

In the stilts group at least 18 patients (75\%) showed weakness in the bilateral tibialis anterior and triceps surae muscles and diminution of muscle stretch reflexes of the bilateral ankles (table). Although 11 clinical findings were significantly different between the stilts and non-stilts groups $\left(\chi^{2}\right.$ test, $\left.P<0.05\right)$, only one, with weakness of the bilateral triceps surae muscles, had both sensitivity and specificity that exceeded 0.95 .

Five patients of the stilts group in whom sensory disturbances were not found during physical examination had mild astasia without abasia. Results of sural nerve conduction velocity and SEP testing were normal in all five patients, and cutaneous vibration and thermal cooling thresholds were normal in three.

\section{STUDY 2}

The bilateral below-knee amputee was able to stand in place while wearing prostheses and had a COP of $51.0(4 \cdot 3) \mathrm{cm} / 30 \mathrm{~s}$. After the dorsiflexion bumpers were detached from the prostheses, he was unable to stand in place and took a step; therefore, the COP was unmeasurable.

\section{STUDY 3}

With ankle-foot orthoses, stability while standing was subjectively judged as much improved by 17 patients, and as improved by five patients. The COPs decreased greatly in seven of the 16 consecutive patients while wearing ankle-foot orthoses (Nos 3 to 9 in fig 2), decreased significantly in another seven patients (Nos 10 to 16 ), and were unmeasurable either with or without orthoses in two (Nos 1 and 2), although the patients claimed improvements. Astasia without abasia was severe in the two patients (Nos 1 and 2) who had severe sensory disturbances and was mild in three patients (Nos 11, 13, and 16) who had no sensory disturbances.

\section{Discussion}

Because astasia without abasia is encountered in various conditions, this study included patients with hereditary motor sensory neuropathy or spinal root lesions who did not show astasia without abasia and healthy volun- 
teers. As there were no significant differences in age and sex ratio between the stilts and nonstilts groups, their clinical findings could be compared to investigate physical factors contributing to astasia without abasia.

Hirayama $e t$ al $^{12}$ reported that the cause of astasia without abasia was a combination of the loss of the ankle pattern, lack of compensatory movements of the hip, and impairment of somatosensory feedback from the legs. However, one patient with progressive spinal muscular atrophy and astasia without abasia had neither weakness of the hip extensor and flexor muscles nor sensory disturbance of the lower limbs. ${ }^{11}$ Therefore, we hypothesise that the most important factor in the development of astasia without abasia is weakness of the triceps surae muscles although disturbance of compensatory postural movements and impairment of sensations are aggravating factors.

In this study the weakness of the bilateral triceps surae muscles was the only one of 28 physical findings that was both sensitive and specific for astasia without abasia. Moreover, as patients without sensory disturbances and without weakness of the iliopsoas and gluteus maximus muscles also had astasia without abasia, these findings also support our suggestion that neither impairment of somatosensory feedback nor disturbance of compensatory postural movements is essential for astasia without abasia.

Although we suggest that weakness of the triceps surae muscles causes astasia without abasia, proving that it does so regardless of compensatory postural movments of the hip and somatosensory feedback from the legs is difficult. The bilateral below-knee amputee is one of the best models for investigating the effect of the strength of the bilateral triceps surae muscles on stability while standing with normal compensatory postural movements of the hip and constant sensory input from the legs. Firstly, we selected an amputee who was thought to have no impairment of compensatory postural movements or somatosensory feedback. The amputee had normal muscular strength, sensations, and SEP results and did not have any disability of standing or walking while wearing prostheses. Secondly, to mimic weakness of the triceps surae muscles, the dorsiflexion bumpers were detached from the artificial feet. The bumpers continuously support the shafts of the prostheses and prevent excessive ankle dorsiflexion while standing. Because they function similarly to the triceps surae muscle, detaching the bumpers can mimic complete paralysis of the bilateral triceps surae muscles. As the interface between the socket and stump is unaltered before and after detaching the bumpers, transmission of tactile information from the prostheses to the stump is considered constant. Therefore, an inability to stand without the dorsiflexion bumpers indicates that the muscular strength of the bilateral triceps surae is essential to maintain a straight posture while standing. Results of this amputee study are consistent with Basmajian's belief that maintaining a standing position requires continuous muscular activity of the triceps surae muscle. ${ }^{12}$

Lack of compensatory postural movements of the hip has been postulated as one of the three conditions contributing to astasia without abasia. ${ }^{12}$ The postural movements supporting the erect stance are organised by using one or a combination of two basic patterns: those of the ankle or the hip. ${ }^{13}$ The dominant frequencies of postural sway in the patient's upright posture are about $1 \mathrm{~Hz},{ }^{2}$ which is identical to the mechanically limited frequencies of the centre of gravity sway when pure hip pattern postural movements are used. ${ }^{14}$ Considering that 18 patients who had astasia without abasia did not show any weakness of the gluteus maximus muscles (table) and results of the amputee study, the $1 \mathrm{~Hz}$ oscillation in the upright posture may not suggest a disturbance of postural movements but compensation of a process by the hip pattern.

Although our study found that an impairment of sensation is not required for this disability to develop, balance control requires continuous regulation and integration of sensory inputs. ${ }^{15}$ Because patients in the stilts group with severe sensory disturbances were very unstable while standing and patients without any sensory disturbance were slightly unstable, impairment of sensation likely worsens astasia without abasia. As a patient who had sensory disturbances and no muscular weakness was not included in this study, it is unclear whether sensory disturbance without muscle weakness can cause astasia without abasia. However, we think that such a patient would be unstable while both walking and standing in place - that is, sensory ataxia.

The treatment for astasia without abasia consists of treatment of the underlying condition, if possible, and compensatory therapy for the weakness of the triceps surae muscles to maintain an upright posture. We suggest that ankle-foot orthoses should be prescribed for patients with this disability to prevent inappropriate ankle dorsiflexion while standing and orthoses are the best method to improve standing balance.

We thank Drs Kazuhiro Inoue and Kumiko Inuyama, Department of Rehabilitation Medicine, University of Occupational and Environmental Health, for referring some patients to us; Saburo Ohmine, Hideo Shitama and Koichi Shinkoda, Rehabilitation Center, University of Occupational and Environmental Health Hospital, for measuring the centre of of foot pressure; and Dr Noboru Iwata, Department of Ergonomics, University of Occupational and Environmental

1 Hirayama K, Kawamura M. Astasia without abasia (able to walk and unable to stand still) a strange disturbance of wank 1991;28:1357-66.

Hirayama K, Nakajima M, Kawamura M, Koguchi Y. Astasia without abasia due to peripheral neuropathy. Arch Neurol 1994;51:813-6.

3 Daniels L, Worthingham C. Muscle testing: techniques of manual examination. 3rd ed. Philadelphia: Saunders,

4 American Academy of Orthopedic Surgeons. Foint motion: method of measuring and recording. Chicago: American Academy of Orthopedic Surgeons, 1965.

5 Haerer AF. Dejong's the neurologic examination. 5th ed. Philadelphia: Lippincott, 1992.

6 Kimura J. Electrodiagnosis in diseases of nerve and muscle. Philadelphia: Davis, 1983.

7 Uozumi T, Tsuji S, Sasaki M, et al. Somatosensory evoked potentials in patients with cervical spondylotic myelopathy. Clin Neurol (Tokyo) 1989;29:558-62. 
8 Ohnishi A, Ikeda M, Yamamoto T, Murai Y. Cutaneous vibration and thermal-cooling threshold in control vibration and thermal-cooling threshold in ${ }^{2}$.

9 Friedmann LW. Rehabilitation of the lower extremity amputee. In: Kottke FJ, Lehmann JF, eds. Krusen's handbook of physical medicine and rehabilitation. Philadelphia: Saunders, 1990:1024-1101.

10 Lehmann JF. Lower limb orthotics. In: Redfor JB, ed. Orthotics etcetera. Baltimore: Williams and Wilkins, 1985 198-351.

11 Ueda $M$, Tsutsui $Y$, Inoue $K$, Hachisuka $K$, Ogata $H$ Plastic AFOs for spinal progressive muscular atrophy with stilts phenomenon. fapanese fournal of Rehabilitatory
Medicine 1994;31:346-9.

12 Basmaiian JV. Lower limbs. In: Basmajian JV, De Luca CJ ed. Muscle alive. 5th ed. Baltimore: Williams and Wilkins, 1985:336-8.

13 Horak FB, Nashner LM. Central programming of postura movements: adaptation to altered support-surface config urations. F Neurophysiol 1986;55:1369-81.

14 Nashner LM, Shupert CL, Horak FB, Black FO. Organization of posture controls: an analysis of sensory and mechanical constraints. Prog Brain Res 1989;80:411-8.

15 Lajoie Y, Teasdale N, Bard C, Fleury M. Attention demands for static and dynamic equilibrium. Exp Brain Res 1993;97:139-44.

\section{Octave Landry's ascending paralysis and the Landry-Guillain- Barré-Strohl syndrome}

\section{Continued from $p 495$} bution materialised, as the celebrated paper by Guillain, Barré, and Strohl describing the illness in two French soldiers.

"The syndrome is characterised by motor disorders, abolition of the tendon reflexes with preservation of the cutaneous reflexes, paraesthesias with slight disturbance of objective sensation, pain on pressure of the muscle masses, marked modifications in the electrical reactions of the nerves and muscles, and remarkable hyperalbuminosis of the cerebrospinal fluid with absence of cytological reaction (albuminocytological dissociation)

This syndrome seemed to us to depend on a concomitan injury of the spinal roots, the nerves, and the muscles, probably of infectious or toxic nature."

The soldiers described both showed gross elevation of cerebrospinal fluid protein $(2.5 \mathrm{~g} / 1$ in the first case) without a cellular reaction. Strohl, whose name is often overlooked, performed the electrophysiological test ("myographic curve"). Osler's 1892 classic The principles and practice of medicine recognised the illness, calling it acute febrile polyneuritis, and Bradford, Holmes, and others regarded it as acute infective polyneuritis.

In 1949 Haymaker and Kernohan commended the
But it was not until 1916 that the next major contri-

eponym Landry-Guillain-Barré syndrome. ${ }^{10}$ But Guillain was angered by the inclusion of Landry's name, ${ }^{11}$ arguing that Landry's acute bulbar form was a separate condition, and since lumbar puncture was not practised until 1891 (Wynter and Quincke) before Landry's time, that the inclusion of his name was "une confusion nosographique absolue".

Barré, a fine clinician, became professor of neurology in Strasburg, concentrating his research on vestibular disorders. He died in 1967

Landry, living for a time in straitened circumstances, had made no further contributions to the subject. His wife, Claire Giustigniani, he described as: "d'une grande beauté, d'une distinction suprême, mais beaucoup plus riche de noblesse que d'argent". A gentle and modest man, he directed a hydrotherapy clinic for nervous diseases at Auteuil, which eventually brought its own success and financial reward. A gifted exponent of the violoncello, he was also an accomplished singer and dancer. He cut an elegant and popular figure in artistic salons. But he was no lounge lizard, occupying his leisure as alpinist, geologist, horseman, and huntsman. Sadly, in his 40th year, Landry attended the penniless, destitute victims of a cholera epidemic in Paris, contracted the illness himself, and died a few days later.

JMS PEARCE 304 Beverley Road Anlaby,
East Yorks HU10 7Bf, UK

1 Landry O. Note sur la paralysie ascendante aigue. Gazette Hebdomadaire de Medicin 1859;6:472-4; 486-8.

Wilks $\mathbf{S}$. Lectures on diseases of the nervous system delivered at Guy's Hospital. London: Churchill, 1878.

Leyden $\mathrm{E}$ von. Ueber poliomyelitis und neuritis. $Z \mathrm{klin}$ Med 1879/80;1:387-8.

4 Bontius J. De medicina indorum (1642). English translation 1769, chapter 1, book IV: cited In: Ralph H Major. Classic descriptions of disease. 3rd ed. Oxford: Blackwell, 1945:605.

5 Pearce JMS. Robert Graves and multiple neuritis. $\mathcal{f}$ Neurol Neurosurg Psychiatry 1990;53:113.

6 Chomel A-F. De l'épidémie actuellement régnante à Paris. F Hebdomadaire de Medecin 1828;1:333 et seq.

7 Graves RJ. Clinical lectures on the practice of medicine. 2n ed. reprinted by New Sydenham Society, London
$1884: 574 ; 579-80$.

8 Dumenil L. Paralysie peripherique du mouvement et du sentiment portant sur les quatre membres. Atrophie des rameaux nerveux des parties paralysies. Gazette Hebdomadaire de Medicin 1864;1:203-6.

9 Guillain G, Barré JA, Strohl A. Sur un syndrome de radiculo-névrite hyperalbuminose du liquide céphalorachidien sans réaction cellulaire. Bull Soc Méd Hôp Paris 1916;40:1462-70.

10 Haymaker W, Kernohan JW. The Landry-Guillain-Barre syndrome: a clinicopathologic report of fifty fatal case and a critique of the literature. Medicine 1949;28 59-141.

11 Guillain G. Radiculoneuritis with acellular hyperalbuminosis of the cerebrospinal fluid. Arch Neurol Psychia 1936;975-90. 